\title{
EDITORIAL
}

\section{Imaging in lung disease}

\author{
M. Decramer, C. Roussos
}

The present supplement of the European Respiratory Journal comprises a number of reviews on Imaging in Lung Disease. It is the product of a symposium held in Barcelona, Spain, on June 23, 2001. The symposium was organized by the European Institute of Healthcare, set up by AstraZeneca. It represents the second symposium of this kind organized by the institute. The goals of the institute were extensively discussed in supplement 34 [1]. The potential role of pharmaceutical companies, together with other and perhaps more logical players in the field such as national and international professional societies, governmental bodies and bodies related to the European Commission, in the postgraduate education of chest physicians was also elaborated upon. The scientific programme of these meetings was designed by an independent programme committee. At the core of this programme committee are the two editors of the present supplement, who were united by nothing less than their commitment to excellence. Other members were: P. Barnes (London, UK), K.F. Chung (London, UK), L. Nicod (Geneva, Switzerland), R. Rodriguez-Roisin (Barcelona, Spain), and J. Verschakelen (Leuven, Belgium). J. Verschakelen played a key role in the programme of the present symposium on Imaging in Lung Disease. The publication of these symposia in a supplement of the European Respiratory Journal, rather than in the European Respiratory Review, is an exception for a company-sponsored event. This exception is justified in the authors' opinion because the programme of the symposium is non-product related, deals with issues of high scientific quality and is independent of company influence. These are the cornerstones of the AstraZeneca commitment to these symposia.

Imaging has become a cornerstone of the diagnosis of lung disease. The development of imaging techniques during the 1980s and 1990s represents one of the most significant areas of progress in medicine. Spiral computed tomography (CT) is of great diagnostic value in many lung diseases; positron emission tomography and digital angiography techniques are widely used; magnetic resonance imaging will probably become gradually more important; and virtual reconstruction techniques may prove to be of clinical value in the future. In the present supplement, the role of imaging in two broad areas, pulmonary embolism and lung cancer, is emphasized. Imaging techniques are playing a growing role in diagnostic algorithms for pulmonary embolism. In addition, their role has become substantially more significant and better defined than in the past in the preoperative staging and follow-up of lung cancer. Low-dose CT may even play a role in screening for lung cancer. Imaging techniques without question also play a key role in the diagnosis of interstitial lung disease, for which open lung biopsy has become redundant because of the improved performance and diagnostic value of imaging techniques. This latter aspect is not developed in the present supplement as it was elaborated on in supplement 32 [2]. Imaging is pivotal to the diagnosis of respiratory infections, but this was addressed in the European Respiratory Journal series "Thoracic Imaging" (see later).

The present supplement complements the "Thoracic Imaging" series, which was edited by P.A. Gevenois, A. Bankier and Y. Sibille [3]. This supplement is not meant to compete with the series but rather to be complementary to it. Whereas the emphasis of the series was on imaging techniques, that of the present supplement is on the place of imaging in the overall clinical diagnostic and therapeutic strategy. The supplement is therefore directed towards the chest physician much more than towards the radiologist, although the imaging expert may find relevant clinical diagnostic and therapeutic information in the issue. In addition, the series covered virtually all aspects of imaging, whereas the present supplement is limited to pulmonary embolism and lung cancer.

The present supplement covers several aspects of the role of imaging in the diagnosis of lung diseases, starting with an overview by MülLER [4] of the development of magnetic resonance imaging and CT, how it developed, current possibilities and how it might develop in the future. The first part then deals with pulmonary embolism. Herold gives an overview of the studies done with spiral CT in pulmonary embolism [5], GoldHABER [6] summarizes the current and future treatment of pulmonary embolism and, finally, Pistolesi and Miniati [7] present and validate a diagnostic algorithm for the diagnosis of pulmonary embolism using clinical symptoms, perfusion scintigraphy and spiral CT. The second part of the supplement addresses lung cancer. VERSCHAKELEN et al. [8] review the role and limitations of $\mathrm{CT}$ in the diagnosis of lung cancer; VANSTEENKISTE [9] summarizes the role of the positron emission tomography scan; Deslauriers [10] gives an overview of the current treatment of lung cancer; and, finally, SHAEFERPROKOP and PROKOP [11] provide insight into the new imaging techniques that may develop into diagnostic strategies in lung cancer. 


\section{References}

1. Decramer $\mathrm{M}$, Roussos CS, Rodriguez-Roisin R. Cytokines and obstructive lung disease: introduction. Eur Respir J 2001; 18: Suppl. 34, 1s-2s.

2. Demedts M, du Bois RM, Nemery B, Verleden GM. Interstitial lung disease: a clinical update. Eur Respir $J$ 2001; 18: Suppl. 32, 1s.

3. Bankier A, Gevenois PA, Sibille Y. Why a series on imaging in the ERJ? Eur Respir J 2001; 17: 328.

4. Müller NL. Computed tomography and magnetic resonance imaging: past, present and future. Eur Respir J 2002; 19: Suppl. 35, 3s-12s.

5. Herold CJ. Spiral computed tomography of pulmonary embolism. Eur Respir J 2002; 19: Suppl. 35, 13s21s.

6. Goldhaber SZ. Modern treatment of pulmonary embolism. Eur Respir J 2002; 19: Suppl. 35, 22s27s.

7. Pistolesi M, Miniati M. Imaging techniques in treatment algorithms of pulmonary embolism. Eur Respir J 2002; 19: Suppl. 35, 28s-39s.

8. Verschakelen JA, Bogaert J, De Wever W. Computed tomography in staging for lung cancer. Eur Respir $J$ 2002; 19: Suppl. 35, 40s-48s.

9. Vansteenkiste JF. Imaging in lung cancer: positron emission tomography scan. Eur Respir J 2002; 19: Suppl. 35, 49s-60s.

10. Deslauriers J. Current surgical treatment of nonsmall cell lung cancer 2001. Eur Respir J 2002; 19: Suppl. 35, 61s-70s.

11. Shaefer-Prokop C, Prokop M. New imaging techniques in the treatment guidelines for lung cancer. Eur Respir J 2002; 19: Suppl. 35, 71s-83s. 